\title{
Abordagem concisa do Latim a partir de uma revisão de literatura
}

\section{Wallace Dantas*}

\begin{abstract}
Resumo: Buscamos, neste artigo, fazer uma abordagem concisa dos pontos altos que compõem a historicidade da língua latina por acreditarmos que é incontestável o seu valor para a língua portuguesa. Este artigo pretende ser apenas um trabalho de divulgação acerca da história da língua latina desde o primeiro documento até os estudos atuais. Acreditamos que, para a devida compreensão de determinados fenômenos concernentes ao latim, é necessário, a partir de suas origens, fazermos uma ligação com o português, pois um está atrelado ao outro e, com certeza, só haverá compreensão daquele através de um bom e fundamentado entendimento deste. Partindo do pressuposto de que o latim é uma língua que ainda vive e que, de uma maneira ou de outra, é usada pela sociedade atual, pretendemos mostrar, a partir de uma abordagem histórica e concisa, a importância dessa língua para a sociedade, mostrando os principais aspectos que constituíram, ao longo de todos esses anos, a língua latina que por sua vez originou o português. Tal abordagem está fundamentada, principalmente, em Bassetto (2001), Cardeira (2008), Gonçalves (2009), Illari e Basso (2009), Marinho (2009) e Viaro (1999).
\end{abstract}

Palavras-chave: Latim. História Concisa. Atualidade. Revisão de Literatura.

\section{Latin concise approach from a literature review}

\begin{abstract}
In this article, we seek to make a concise approach to the highlights that make up the historicity of the Latin language because we believe that its value for the Portuguese language is undeniable. In view of this, this article intends to be only a work of dissemination about the history of the Latin language from the first document to the current studies. We believe that, for the proper understanding of certain phenomena concerning Latin, it is necessary, from its origins, to make a connection with Portuguese, since one is linked to the other and, certainly, there will only be understanding of that through a good and reasoned understanding of this. Based on the assumption that Latin is a language that still lives and that, in one way or another, it is used by today's society, we intend to show, from a historical and concise approach, the importance of this language for society, showing the main aspects that constituted, throughout all these years, the Latin Language that in turn originated Portuguese. Such an approach is based, mainly in Bassetto (2010), Cardeira (2008), Gonçalves (2009), Illari and Basso (2009), Marinho (2009) and Viaro (1999).
\end{abstract}

Keywords: Latin. Concise history. Present. Literature review.

\section{Considerações Iniciais}

A beleza e o encantamento da língua latina, dentre outros motivos que poderiam aqui ser elencados, se dão por ela ser o idioma que origina todas as línguas românicas. Vislumbrando tal assertiva, buscamos, neste trabalho, fazer uma abordagem concisa dos pontos altos que compõem a historicidade ${ }^{1}$ dessa língua a partir de uma revisão de

\footnotetext{
* Atualmente, mestrando pelo Programa de Pós-Graduação em Linguagem e Ensino da Universidade Federal de Campina Grande - PPGLE/UFCG. MBA em andamento em Gestão Escolar pela Universidade de São Paulo USP. ORCID: https://orcid.org/0000-0002-9716-644X. E-mail: wallace.dantas@bol.com.br.

1 A "historicidade" a qual nos referimos é a mesma já explicitada por Athayde (2014) quando afirma que esse termo está atrelado às ações humanas de transformação dentro de um ponto de vista espacial e temporal. Dialogamos com essa ideia, tendo em vista que acreditamos ser impossível falar da história do latim sem
} 
literatura ${ }^{2}$.

Acreditamos que para compreendermos determinados fenômenos concernentes ao latim devemos ir às suas origens, sempre fazendo uma ligação com o nosso português, pois um está atrelado ao outro e, com certeza, só poderemos compreender aquele através de um bom e fundamentado entendimento deste e vice-versa.

Não queremos, neste artigo, defender que, pelo suposto ${ }^{3}$ desuso do latim nos dias de hoje, essa língua seja difícil (CORDEIRO; LEITE, 2017), nem tampouco acreditamos que defendermos a importância do conhecimento do latim para o bom uso da língua portuguesa seja uma falácia, como já apontado também por Cordeiro e Leite (2017). Pensamos que uma revisão de literatura, a partir de autores nacionais, possa contribuir com a evidência que deve ser dada à língua latina, assim como porpor, aos estudiosos da atualidade, uma leitura mais didática, sejam aos estudiosos iniciantes, como também àqueles que necessitam, numa única fonte, se debruçar com as ideias de autores que tomam o latim como fonte primária de seus estudos.

Por fim, não adentraremos nos aspectos culturais da língua latina de forma exaustiva, mas evidenciaremos apenas os aspectos históricos. No entanto, não discutir neste texto os aspectos para além da cultura, do ensino e da literatura da língua latina, não significa dizer que esses não sejam importantes. Alguns autores já realizarem essa tarefa, como podemos ver nos escritos de Fortes (2015); Fortes e Prata (2015) quanto à cultura; Cacho (2001), Fiorin (1991), Cordeiro e Leite (2017) quanto ao ensino do latim na educação básica; Leite e Castro (2014) quanto ao ensino do latim na universidade e por graduandos em Letras, e, de forma mais instigante, um "latim para o novo milênio (MINKOVA; TUNBERG, 2008). Com isso, com vistas a atingir o objetivo que traçamos para este texto, propomos a seguinte estrutura: no próximo ponto, mostraremos, concisamente, o latim de suas origens à atualidade. Em seguida, temos as considerações finais.

\section{O latim: das origens à atualidade}

O nosso português nasceu do latim, que por sua vez teve como berço o centro da Roma antiga, tendo seu apogeu entre a fundação da própria Roma, por Rômulo em 753 a.C., até a deposição do último imperador Rômulo Augústulo em 476 d. C..

mencionarmos a ação humana (transformação, avanço, descaso e, mais atualmente - e considerando a ideia deste artigo - a valorização devida à língua latina) sobre essa língua que é cara ao nosso português.

2 Principalmente, fundamentaremos nossas reflexões a partir de autores brasileiros. Quando necessário, mencionaremos autores estrangeiros.

${ }^{3}$ Usamos a palavra "suposto" porque, no decorrer do texto, tentaremos mostrar a importância do conhecimento da língua latina e sua importância. 
Alguns estudiosos (BRAGANÇA JR., 2008; ILARI e BASSO, 2009; VIARO, 1999) acreditam que o latim tenha sido falado primeiramente na região do Lácio por volta do século XI a.C. (nesse momento, temos o que a maioria dos pesquisadores chama de Latim Arcaico), no entanto, os escritos mais antigos datam dos séculos VII e VI a. C..

Após o latim arcaico, temos um momento que corresponde ao primeiro século a.C até os anos iniciais da Era Cristã, momento esse denominado de latim clássico que corresponde ao estilo literário da época. "São desse período a prosa elaborada do político, filósofo e orador Cícero, a poesia lírica ${ }^{4}$ e a épica nacional de Virgílio, com as suas Bucólicas e a sua Eneida, e a lírica amorosa de Catulo, Propércio, Tibulo, Horácio e Ovídio. (...)" (GONÇALVES, 2009, p. 11-12)

É desse período de produções artisticamente bem elaboradas que extraímos o latim ensinado atualmente, posto os autores mencionados terem tido uma preocupação em elaborar seus escritos. É importante lembrarmos que concomitante a esse período, segundo Gonçalves (2009), podemos distinguir outro estrato que é, então, o latim culto que era falado pela classe culta e dominante de Roma e que foi a base para o latim clássico. A exemplo desse período temos as cartas de Cícero para seu irmão e as cartas de Sêneca para sua mãe. É sabido ainda que até certo tempo atrás - quando o latim era mais usado nas celebrações católicas e nas Escolas Médias - eram ensinados, respectivamente, o latim eclesiástico ou culto e o latim literário ou clássico, no entanto, a variedade do latim que deu origem a nossa língua foi o latim vulgar - não apenas ao português, mas a todas as línguas românicas.

Ilari e Basso (2009, p. 15-16) nos dizem que o latim vulgar deve ser entendido em uma palavra - Vernáculo "que caracteriza um modo de aprender as línguas: o aprendizado que se dá, por assimilação espontânea e inconsciente, no ambiente em que as pessoas são criadas. A vernáculo opõe-se tudo aquilo que é transmitido através da escola." Com isso, percebemos que o que falamos hoje nasce desse latim, daí a necessidade de entendermos de uma maneira mais simples e didática nossa língua materna. Não devemos ainda esquecer que o latim vulgar foi uma variante principalmente da língua falada que, depois das conquistas militares que culminaram em um período de estabilidade para o Império Romano, passou a ser usada pela maioria dos territórios conquistados. "Nesse período, acredita-se que o latim vulgar apresentou uma relativa uniformidade em uma grande área geográfica que correspondia à boa parte da Europa ocidental” (ILARI; BASSO, 2009, p. 17). No entanto, essa unidade não perdurou por muito tempo, nascendo "um período de fragmentação provocado pelas grandes invasões 'bárbaras"” (ILARI; BASSO, 2009, p. 17)

\footnotetext{
${ }^{4}$ Para aprofundamento do que Goçalves (2009) nessa citação chama de "poesia lírica" ao se referir a Virgílio, assim como a lírica de Catulo, sugerimos a leitura do texto de Aída Costa "A poesia lírica em Roma".
} 
nascendo assim, ao final do século X, um "mosaico de falares", tanto de grande quanto de pequeno prestígio. Para muitos estudiosos, é nesse momento que temos o nascimento da România.

România equivale a todo o Império Romano: Roma e todas as regiões conquistadas. É importante, neste momento, fazermos uma distinção entre România Atual e România Perdida. Para Marinho (2009), a primeira corresponde às regiões do mundo onde se falam língua neolatina, nesse aspecto, segundo o autor mencionado, a América do Sul não faz parte do Império Romano, mas está inserida na România Atual, devido ao fato de uma extensa maioria de seus habitantes falar português ou espanhol. A segunda, por sua vez, corresponde à parte do Império que não preservou a tradição da língua latina, como é o caso da Grã-Bretanha que fala inglês, língua essa derivada do tronco germânico.

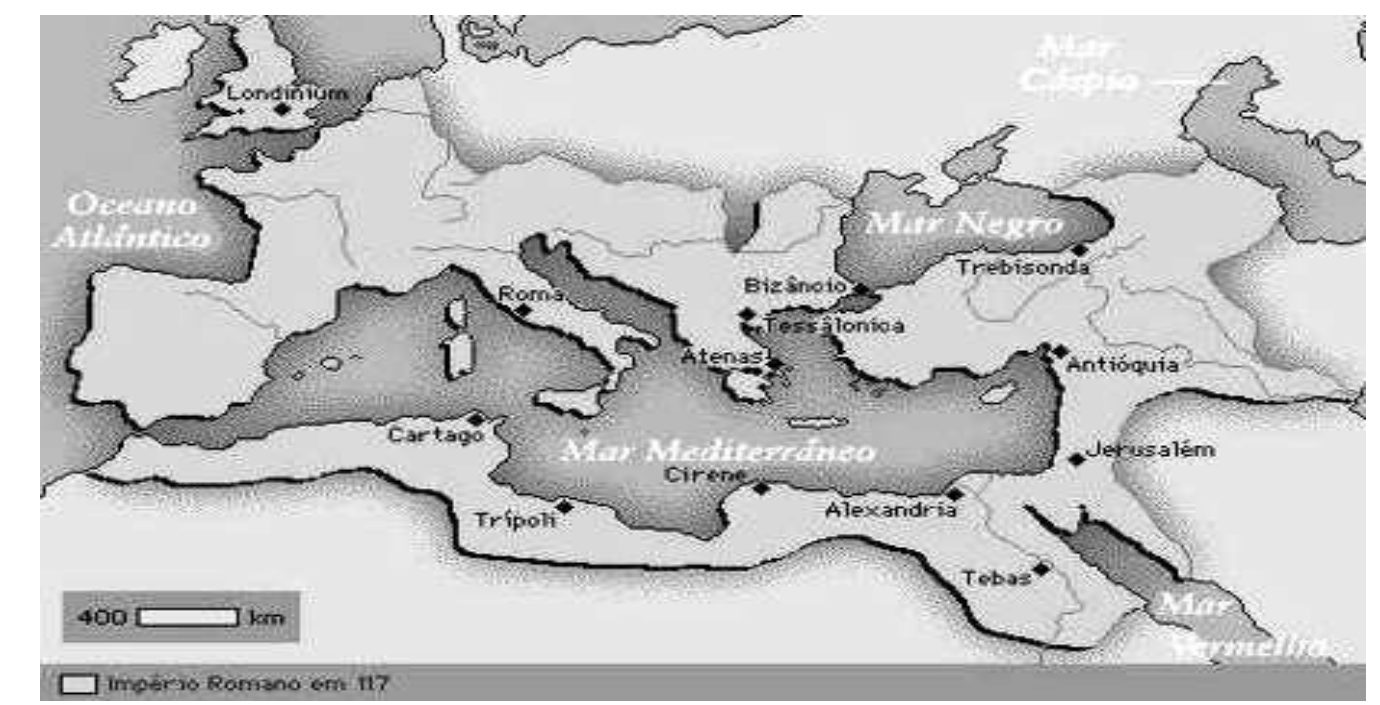

(Imagem 1: Mapa que mostra toda a România ou o Império da Roma antiga. Fonte: MARINHO, 2009, p. 36)

Logo após essa efervescência, alguns desses falares foram ganhando certo prestígio e, a partir desse momento, foram se transformando nas línguas românicas que conhecemos atualmente: o romeno, o italiano, o sardo, o reto-românico, o occitano, o francês, o catalão, o espanhol, o galego e o português.

Tais línguas foram surgindo de acordo com as regiões dialetais do Império Romano, a saber: România Oriental e România Ocidental. Essa distinção entre as duas regiões aconteceu a partir da Isoglossa Spezia-Rimini, uma espécie de linha imaginária existente entre as duas cidades italianas que a nomeiam. Diante disso, tudo o que estava localizado ao norte e a oeste dessa isoglossa pertencia à România Ocidental, e o que correspondia ao sul e ao leste dizia respeito à România Oriental. Visto isso o português, o galego, o espanhol, o catalão, o francês, o franco-provençal, o rético e as línguas do norte da Itália eram da România Ocidental. Já o romeno, o dalmático e as línguas do centro e do 
sul da Itália (inclusive o toscano, que, na realidade, é o italiano propriamente dito) diziam respeito à România Oriental.

Voltando ao latim vulgar, faz-se necessária uma discussão no tocante aos estudos mais atuais sobre o assunto. Marinho (2009), citando Mello (1951), Cunha (1975), Auerbach (1972), Lausberg (1974), Câmara Jr (1979), nos mostra que o latim Vulgar foi falado por todas as camadas da sociedade naquela época, não se restringindo, portanto, às camadas menos favorecidas da sociedade. Ele nos diz ainda que o latim vulgar é atribuído ao povo romano e romanizado, ou seja, a todos os habitantes do Império, não fazendo uma distinção se o cidadão é ou não culto/letrado. Para provar sua assertiva, Marinho (2009) cita Mello (1951, p. 99 -100) inicialmente. Vejamos a citação:

Cumpre também ressaltar que esse latim de que as línguas românicas são continuações históricas tem um aspecto bastante diverso daquela língua polida e requintada, que se deveria aprender nos ginásios e colégios, aquela língua de Cícero, Virgílio, Horácio, Catulo, etc. O latim ponto de partida dos idiomas românicos é o latim vulgar, ou, por melhor nome, o latim coloquial, isto é, a língua viva entre o povo romano e povos romanizados, língua instrumento de comunicação diária, com finalidades práticas e imediatas.

Por sua vez, e a partir de toda a exposição feita em seu texto, embasado nos autores já citados, Marinho (2009) ainda nos diz que

Portanto, o latim literário era, na verdade, o ideal linguístico, expressão da língua latina que aparecia na literatura de grandes autores, como Cícero ou Virgílio. Seria a língua gramatical, que, com efeito, não é falada por ninguém. A realidade linguística é a fala, com suas variações diatópicas, diastráticas e, até mesmo, diafásicas. (p. 41)

Para comprovar sua tese, Marinho (2009, p. 41) também nos traz uma demonstração das variações mencionadas na citação acima. Vejamos:

\begin{tabular}{|l|c|c|c|}
\hline \multirow{2}{*}{ Modalidades } & \multicolumn{3}{c|}{ Variedades } \\
\cline { 2 - 4 } & Diatópica & Diastrática & \multicolumn{1}{c|}{ Diafásica } \\
\hline Sermo literarius & $\ldots \ldots . \cdots \cdots$ & Todos os registros \\
\hline $\begin{array}{l}\text { Sermo vulgaris } \\
\text { (latim vulgar) }\end{array}$ & Sermo urbanus & $\begin{array}{l}\text { Sermo urbanus } \\
\text { Sermo plebeius }\end{array}$ & Todos os registros \\
\cline { 2 - 4 } & Sermo provincialis & $\begin{array}{l}\text { Sermo urbanus } \\
\text { Sermo plebeius }\end{array}$ & Todos os registros \\
\hline & Sermo rusticus & Sermo plebeius & Todos os registros \\
\hline
\end{tabular}

Quadro 1: Variações do Latim conforme Marinho (2009)

Temos as modalidades escrita e falada. Ambas podem ser realizadas em todos os registros linguísticos. A escrita, sermo literarius, por ser um ideal, obviamente não possui variedades em nível diatópico ou diastrático. No sermo vulgaris, latim vulgar, ocorre o contrário, uma vez que a variação é inerente a essa modalidade. $\mathrm{Na}$ esfera diatópica, o sermo urbanus representa o centro do Império. Já o sermo provincialis, como o nome sugere, se refere às províncias, espaços distantes de 
Roma. Por fim, o sermo rusticus reproduz a fala do interior, tanto de Roma, quanto das províncias. Diastraticamente, vemos uma divisão bipartida em sermo urbanus e sermo plebeius, que aludem respectivamente aos falares mais e menos culto. $\mathrm{O}$ interior, habitado por muitos camponeses e pessoas iletradas, apresentava somente o sermo plebeius.

Dessa forma, o habitante culto de Roma, como Cícero, não falava latim literário. Sua língua, na verdade, era o latim vulgar (sermo vulgaris), urbanus (geograficamente) e urbanus (socialmente). Um plebeu romano falava latim vulgar urbanus (geograficamente) e plebeius (socialmente). Um cidadão culto do norte da África, Santo Agostinho por exemplo, falava latim vulgar provincialis (geograficamente) e urbanus (socialmente). (MARINHO, 2009, p. 42)

À luz de todo o exposto, podemos concluir que "o latim vulgar foi a modalidade falada de nossa protolíngua, realizada por todas as pessoas (de qualquer classe social) do vasto Império Romano em todas as épocas da latinidade” (MARINHO, 2009, p. 42).

Percebemos, então, que o latim se desenvolve de maneira assombrosa. Tal avanço pode ser visto a partir do primeiro documento escrito, a Fíbula de Preneste ou Fíbula Praenestina, do século VII a. C., passando pelos escritores - considerando o latim literário - e através de documentos que retratam a documentação de falares vulgares, tais como o Appendix Probi que é um dos documentos mais importantes para o estudo do latim vulgar de que se tem conhecimento (CARDEIRA, 2006).

A Fíbula de Preneste consiste em um broche, uma fivela em ouro, de aproximadamente $11,7 \mathrm{~cm}$ de cumprimento. Como já mencionado, tal objeto data do século VII a. C. e traz uma mensagem gravada no seu corpo. Tal mensagem, em latim, é transcrita a seguir:

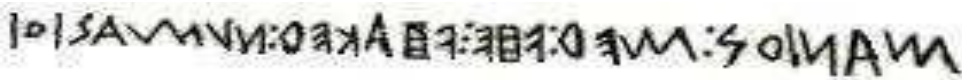

Imagem 2: Fonte: <http://hortushesperidum.blogspot.com/2016/12/fibula-depraeneste-la-inscripcion.html> Acesso em março de 2020.

Para o nosso entendimento quanto à leitura, transcrevemos invertidamente MANIOS MED FHE FHAKED NUMASIOI

Em latim clássico, vamos ter a seguinte escrita: MANIUS ME FECIT 
Em português, por sua vez, temos:

MANIUS ME FEZ PARA NUMASIO

Quanto ao Appendix Probi, o que sabemos é que se trata de um escrito anônimo, constituído de 227 verbetes, talvez do século III a.C., que diz respeito a uma lista de formas "X non Y" que funcionava como uma espécie de conjunto de regras, dizendo como as pessoas deveriam falar e escrever, ou seja, ao invés de usarem "X" deveriam usar "Y".
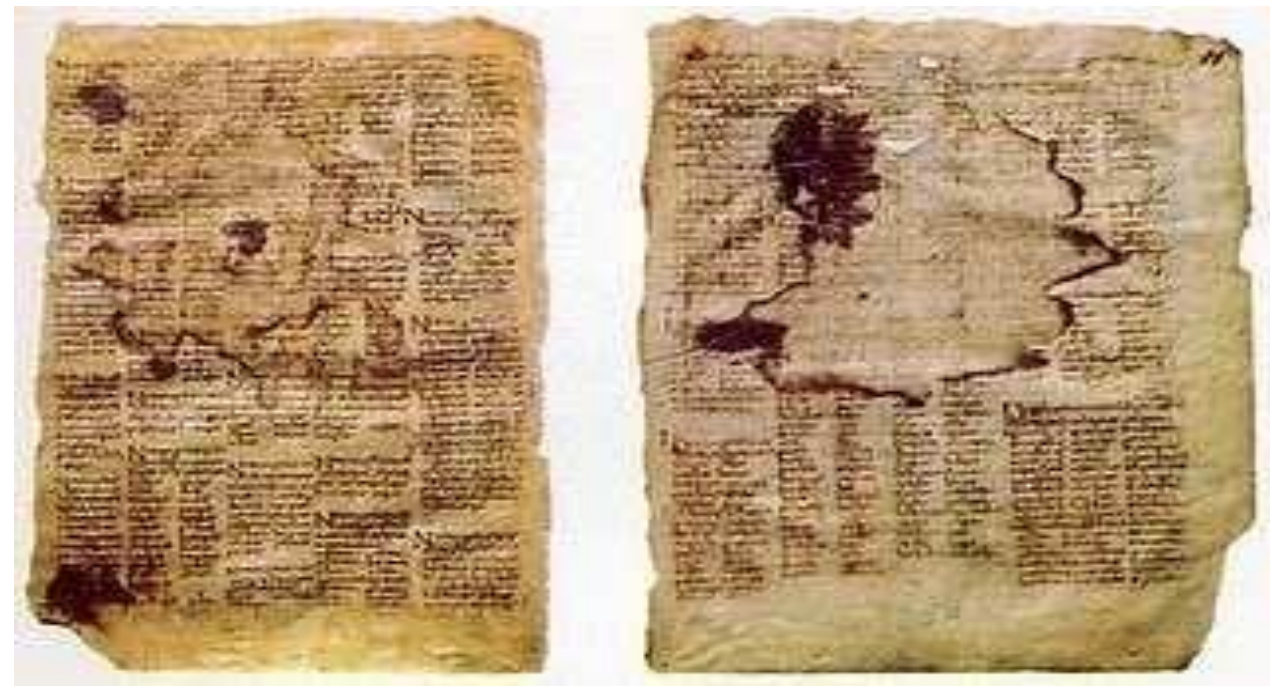

(Imagem 3: extraída do blog pessoal da Prof ${ }^{\mathrm{o}} \operatorname{Dr}^{\mathrm{a}}$ Lúcia Deborah - Doutora em Língua Portuguesa pela Universidade Estadual do Rio de Janeiro - Disponível em: http://luciadeborah.blogspot.com/2011/03/appendix-probi-para-alunos-de- filologia.html)

Vemos que a língua latina, em todo o percurso aqui mostrado, se desenvolveu como qualquer outra língua deixando traços bastante peculiares. Atualmente, por exemplo, o latim é essencialmente trabalhado a partir dos autores literários e, quando necessário, são mencionados os casos do latim vulgar visando um entendimento de determinadas palavras da língua portuguesa.

Quanto ao latim literário (não poderíamos deixar de mencioná-los dada a importância que a ele é concedida) temos, no latim arcaíco, os testemunhos de: Lívio, Andronico, Névio, Ênio, Catão, as comédias de Plauto e Terêncio. César, Cícero, Ovídio, Horário Virgílio e Catulo compõem a fase clássica da Literatura Latina. No Latim PósClássico vem a narrativa de Apuleio, Pérsio, Juvenal, Marcial, Vitrúvio, Tácito, Petrônio, Plínio, Sêneca e autores cristãos, como Amiano, Marcelino, Lactânio, Ausônio, Santo Agostinho, Carísio, Santo Ambrósio, e, na Vulgata - tradução latina da Bíblia, temos São Jerônimo, cujo estilo fundamenta toda a Idade Média. Diante disso, desde Varrão, a Língua latina sofre normatização que é reforçada por Quintiliano, Donato, Macróbio, Consêncio, Pompeio, Sidônio Apolinário (VIARO, 1999). 
Como é perceptível, o latim literário corresponde à modalidade escrita. Visando a um entendimento didático, Marinho (2009, p. 43) nos traz um quadro que periodiza a escrita latina. Quadro esse apresentado, primeiramente por Faria (1970) como deixa claro o autor. Lembrando que para cada estágio da língua nos deparamos com o período, com as características e com os escritores. Vamos ao quadro:

\begin{tabular}{|c|c|c|}
\hline ESTÁGIOS DO LATIM & CARACTERÍSTICA & ESCRITORES \\
\hline $\begin{array}{l}\text { Pré-histórico } \\
\text { XI a.C. a VII a.C. }\end{array}$ & Sem documentação. & \\
\hline $\begin{array}{l}\text { Proto-histórico } \\
\text { VII a.c. a } 240 \text { a.c. }\end{array}$ & $\begin{array}{l}\text { Marca o surgimento do primeiro } \\
\text { documento: a } \\
\text { Fíbula de Preneste (séc. VII } \\
\text { a.C.). Outros } \\
\text { documentos: Lei das Doze } \\
\text { Tábuas (séc. Va.C.: } \\
\text { origem do Direito Romano) e } \\
\text { Scipionum Elogia } \\
\text { (séc. III a.C.: inscrições } \\
\text { funerárias). }\end{array}$ & \\
\hline $\begin{array}{l}\text { Arcaico } \\
240 \text { a.c. a } 81 \text { a.c. }\end{array}$ & $\begin{array}{l}\text { Aparecem os primeiros textos } \\
\text { literários, porém a } \\
\text { linguagem não é tão rebuscada } \\
\text { quanto a do } \\
\text { período clássico. Alguns } \\
\text { poemas gregos foram } \\
\text { traduzidos ao latim. }\end{array}$ & $\begin{array}{l}\text { Lívio Andrônico, } \\
\text { Ênio, Névio, Lucílio, } \\
\text { Plauto, Terêncio e } \\
\text { Catão. }\end{array}$ \\
\hline $\begin{array}{l}\text { Clássico } \\
81 \text { a.C. a } 17 \text { d.C. }\end{array}$ & $\begin{array}{l}\text { Período de perfeição na prosa e } \\
\text { na poesia. }\end{array}$ & $\begin{array}{l}\text { Cícero, } \quad \text { César, } \\
\text { Salústio, Lucrécio, } \\
\text { Catulo, Virgílio, } \\
\text { Horácio, Ovídio, Tito } \\
\text { Lívio e C. Galo. }\end{array}$ \\
\hline $\begin{array}{l}\text { Pós-clássico } \\
17 \text { d.C. a V d.C. }\end{array}$ & $\begin{array}{l}\text { Existem ainda grandes obras } \\
\text { literárias, mas sem a } \\
\text { pureza nem a perfeição } \\
\text { clássica. Muitos escritores } \\
\text { não são originários da ltália. }\end{array}$ & $\begin{array}{l}\text { Fedro, Sêneca, } \\
\text { Lucano, } \\
\text { Marcial,Juvenal, } \\
\text { Tácito, Plínio (o } \\
\text { Jovem e o Velho), } \\
\text { Quintiliano e } \\
\text { Petrônio. }\end{array}$ \\
\hline
\end{tabular}

Quadro 2: Períodos da escrita da língua latina conforme Marinho (2009) a partir de Faria (1970)

É na Idade Média que o latim adquire o status de Língua Universal (Viaro, 1999, p. 8): 1) as leis francesas são escritas em latim até o século XVI; 2) as autoridades escrevem tudo em latim, como, por exemplo, as etimologias de Isidoro de Sevilha; 3) os tratados de Boécio; 4) os livros de medicina, como os de Marcelo Empírico e Obribásio; 5) a culinária de Apício; 6) a 
medicina veterinária de Vegeto Renato; 7) e, acima de tudo, os religiosos, através da Bíblia.

Para Bragança Jr (2008, p. 79), latim medieval pode ser definido como

modalidade lingüística portadora da cultura cristã e greco-latina, que se desenvolveu a partir do chamado latim vulgar, assimilando, contudo, no ambiente cultural da vida eclesiástica, as lições dos mestres da Antigüidade Clássica.

No Renascimento, o modelo seguido para a sintaxe e para o estilo do desenvolvimento das línguas modernas foi o latim, assim, como também o esquema gramatical sobre o qual são descritas. É nesse período da Renascença que temos o que podemos chamar aqui de "vestígios do latim tardio" (GONÇALVES, 2009), posto que os modelos do latim clássico perpassaram todo um vasto período de séculos, sendo seguido ou imitado na época do Renascimento, o que para alguns autores é chamado de latim pósclássico (MARINHO, 2009 e VIARO, 1999 - ver tabela anterior). Evidentemente não temos aqui o latim clássico na sua igualdade, mas uma tentativa de preservação dos modelos latinos, mesmo em momentos de criação de dialetos diversos, que, em sua maioria, se afastavam mais e mais do latim. Alguns exemplos que podemos mostrar desde a Época Medieval até momentos posteriores ao Renascimento são: a tradução latina dos textos bíblicos, a Vulgata, de São Jerônimo dos fins do século IV, os documentos portugueses da administração e legislação datados do século XI, a monografia de Karl Max sobre a filosofia do grego Epicuro que foi toda escrita em Latim. (GONÇALVES, 2009)

$\mathrm{Na}$ atualidade, porém, além das missas, temos as descrições da Zoologia e da Botânica que são todas em Latim. Na área jurídica, por exemplo, temos as seguintes expressões: habeas corpus, alibi, data venia. Fora do contexto jurídico, quem nunca

mandou um curriculum vitae? Quem nunca ouviu falar de renda per capita? Ou pensou em fazer uma pós-graduação lato sensu? Ou ouviu que alguém é doutor honoris causa? Quem nunca fez um P.S. ao fim de uma carta? Ora, isso também é latim: post scriptum. Essa antiga língua de Roma está nas tecnologias mais modernas, está na fecundação in vitro, nas invenções mais recentes: está, por exemplo, no fax (abreviação de fac simile, que significa "faça de maneira semelhante", não é isso que faz o fax?). Mesmo muitas palavras importadas do inglês remontam ao latim: na Informática usa-se o verbo deletar, do inglês to delete, que vem, por sua vez, do verbo deleo em latim, que significa "destruir". De tão entranhado na nossa língua, o latim até se confunde com ela: idem é latim, a expressão grosso modo também (por isso, é errado dizer "a grosso modo"), o supra summum, o et caetera, até a expressão vulgo, quando dizemos José Carlos vulgo Zeca. E há muito, muito mais: expressões como a priori, alter ego, causa mortis, ex libris, exempli gratia, Homo sapiens, in continenti, in loco, ipsis litteris, lapsus linguae, modus vivendi, mutatis mutandis, pari passu, persona non grata, ad hoc, sine qua non, scilicet, sic, status quo, carpe diem, sui generis, ab imo pectore, tabula rasa, vade mecum, vade retro, Aedes aegypti, só para citar as mais comuns, dão um sabor todo especial à redação de um texto e- por que não? - à fala, sem falar de provérbios como alea jacta est, cogito ergo sum, mens sana in corpore sano. 
(VIARO, 1999, p. 03)

Percebemos, portanto, que além de uma historicidade singular, o latim é essencial para que venhamos compreender o nosso idioma, além, é claro, de servir como auxílio adequado para aprimoramento de nossa visão de mundo, ampliando nosso modo de pensar, na nossa vivência etc.

Concordamos com Viaro (1999) quando diz que

Aquele que entende bem a mensagem que o latim passa em seus textos se questionará melhor e verá que antes de nossos valores, havia outros, muito distintos, mas perfeitamente coerentes, que merecem nossa admiração e respeito. Longe de ser retrógrado, o estudo do latim associado ao estudo da vida social em Roma nos faz vislumbrar quanta coisa mudou e quanta coisa ainda continua surpreendentemente do mesmo jeito que era, muitas vezes, apenas com os nomes trocados. (p. 89)

\section{Palavras Finais}

Como falado no início do texto que o leitor tem em mãos, o nosso objetivo principal foi trazer à luz uma abordagem concisa, ao mesmo tempo pertinente, no que concerne aos estudos da língua latina. Trocando em miúdos, certamente informações que para o ponto de vista do leitor são importantes podem ter sido aqui omitidas, mas acreditamos que chegamos ao objetivo proposto, a partir de uma revisão de literatura.

Ficou claro que não existe uma forma que dissocie o latim do português, posto aquele ser o criador deste. E, deu ainda para perceber que o estudo atual do nosso português exige um mínimo de conhecimento latino, haja vista, por exemplo, os radicais gregos e latinos que são estudos no decorrer de nossa escolaridade, seja em nível de fundamental quanto de médio, principalmente.

Que, cada vez mais, possamos dar ao Latim seu devido valor!

E, encerramos com o discurso do Professor Eduardo Viaro da USP quando diz que

não é difícil concluir que a importância da língua latina hoje não diminuiu em nada ao longo dos tempos. Ela continua sendo o cerne de nosso idioma e a principal chave para a compreensão dele. Sem a base latina chegaremos à conclusão de que o português é uma língua com muito pouca produtividade do ponto de vista das raízes, o que não é verdade. (VIARO, 1999, p. 10)

\section{Referências}

ATHAYDE, Milton. Historicidade. Laboreal, v. 10, n. 1, jul. 2014, p. 98-100. 
AUERBACH, Erich. Introdução aos Estudos Literários. 2a ed. São Paulo: Cultrix, 1972.

BASSETTO, Bruno Fregni. Elementos de filologia românica. São Paulo, EDUSP, 2001.

BRAGANÇA JÚNIOR, Á. A. Marcas do latim medieval na Peregrinatio Aetheriae - Alguns comentários. Principia: Revista do Departamento de Letras Classicas e Orientais do Instituto de Letras da UERJ, Rio de Janeiro, v. 17, n. 1, p. 77 - 86, 2008.

CACHO, Joaquín Fernandéz. Didáctica del latín. Zaragoza: Instituto de Ciencias de la Educación, 2001.

CARDEIRA, Esperança. O essencial sobre a História do Português. Lisboa: Caminho, 2006. (Coleção $O$ Essencial)

COSTA, Aída. A poesia lírica em Roma. Revista de História, $\mathrm{n}^{\circ} 27$, s/d

CORDEIRO, Iana Lima; LEITE, Leni Ribeiro. O latim como ferramente de expansão do vocabulário do português. Codex - Revista de Estudos Clássicos, Rio de Janeiro, v. 5, n. 2, jul;/dez. 2017, p. 29-48. DOI: http://dx.doi.org/10.25187/codex.v5i2.12077 .

FARIA, Ernesto. Fonética Histórica do Latim. $2^{\text {a }}$ ed. Rio de Janeiro: Acadêmica, 1970.

FIORIN, José Luiz. Letras clássicas no $2^{\circ}$ grau: competência textual e intertextual. Anais do II Congresso Nacional de Estudos Clássicos. Mito, religião e sociedade. São Paulo: SBEC, vol. 1, 1991; p. 514-519.

FORTES, Fábio. Latim e linguística: concepções de linguagem e ensino. In: FORTES, Fábio;

PRATA, Patrícia. O latim hoje: reflexões sobre cultura clássica e ensino. Campinas: Mercado de Letras, 2015; p. 119-130.

FORTES, Fábio; PRATA, Patrícia. A sobrevivência do latim. In: FORTES, Fábio; PRATA, Patrícia. (Org.). O latim hoje: reflexões sobre cultura clássica e ensino. Campinas: Mercado de Letras, 2015; p. 23-39.

GONÇALVES, Rodrigo Tadeu. Língua Latina. Curitiba: IESDE, 2009.

ILARI, Rodolfo. BASSO, Renato. O Português da gente: a língua que falamos, a língua que estudamos. $2^{\text {a }}$ ed. São Paulo: Contexto, 2009.

LEITE, Leni Ribeiro. CASTRO, Marihá Barbosa. O ensino de língua latina na Universidade brasileira e sua contribuição para a formação do graduando em Letras. Organon, v. 29, n. 56. Porto Alegre: 2014. p. 223-244. Disponível em: https://seer.ufrgs.br/index.php/\%20organon/article/view/43622. Acesso: 15 de maio de 2020.

MARINHO, Marco Antônio Ferreira. Do latim ao português: percurso histórico dos sufixos -dor e -nte. Rio de Janeiro, UFRJ, 2009, 212 p. Tese (Doutorado) Programa de PósGraduação em Letras Vernáculas, Universidade Federal do Rio de Janeiro, Rio de Janeiro, 2009.

MELlO, Gladstone C. de. Iniciação à Filologia Portuguesa. $3^{\mathrm{a}}$ ed. Rio de Janeiro: Acadêmica, 1951. 
MINKOVA, Milena; TUNBERG, Terence. Latin for the new millenium. Mundelein: BolchazyCarducci, 2008.

VIARO, Mário Eduardo. A importância do latim na atualidade. Revista de ciências humanas e sociais, São Paulo, Unisa, v. 1, n. 1, p. 7-12, 1999.

Data de registro: $24 / 12 / 2019$

Data de aceite: $05 / 05 / 2020$ 